\title{
LA FUNCIÓN SOCIAL DE LA PROPIEDAD EN LA CONSTITUCIÓN ARGENTINA: TRES MOMENTOS DEL SIGLO XX.
}

\section{THE SOCIAL FUNCTION OF PROPERTY IN ARGENTINA'S CONSTITUTION: THREE MOMENTS IN THE 2OTH CENTURY}

\author{
Horacio Javier Etchichury \\ Universidad Nacional de Córdoba / CONICET
}

SUMARIO: I. INTRODUCCIÓN.- II. EL DERECHO DE PROPIEDAD EN LA CONSTITUCIÓN DEL SIGLO XIX.- III. 1949: UN NUEVO CONSTITUCIONALISMO, UN NUEVO DERECHO DE PROPIEDAD.- IV. 1957: UNA REFORMA QUE NO ALCANZÓ AL DERECHO DE PROPIEDAD.- V. 1994: NUEVAS PAUTAS PARA EL DERECHO DE PROPIEDAD.- VI. PALABRAS FINALES.

Resumen: Este artículo examina cómo la noción de "función social de la propiedad" se integró a la Constitución argentina (CA). Luego de describir la fómula clásica sobre derecho de propiedad adoptada en la CA de 1853, se expone cómo la reforma constitucional de 1949 adoptó la función social de la propiedad" y cómo esa nueva constitución fue derogada por un gobierno militar en 1956. Luego se revisa el intento fallido de restaurar la función social de la propiedad en 1957. La sección final analiza el impacto de la reforma de 1994 en el alcance del derecho de propiedad.

\begin{abstract}
This article examines how the notion of "social function of property" became part of Argentina's Constitution (AC). After describing the classical property clause adopted in $1853 \mathrm{AC}$, the article shows how the 1949 constitutional reform adopted the social funcion of property and how that new constitution was abrogated by a military government in 1956. The article reviews the 1957 failed attempt to restore the social function of property. The final section analyzes the impact of the 1994 constitutional reform on the scope of the right to property.
\end{abstract}

Palabras clave: Propiedad, Constitución, Función social de la propiedad, Argentina

Key Words: Property, Constitution, Social function of property, Argentina

\section{INTRODUCCIÓN}

En este artículo nos proponemos revisar la trayectoria de la noción de "función social de la propiedad" en la Constitución argentina (CA). En primer término exponemos la modalidad con que el derecho de propiedad se consagró en la Constitución de 1853 (CA1853), para luego explicar cómo la función social se adoptó en la Constitución de 1949 (CA1949), aprobada durante el gobierno del 
Partido Peronista (o Justicialista) y derogada poco después de la caída de Juan Domingo Perón. Presentamos a continuación el intento fallido de restituir la "función social" en 1957. Finalmente, indagamos los efectos de la reforma de 1994 en el alcance del derecho de propiedad, para determinar si la "función social" ha sido adoptada bajo una denominación diferente.

\section{EL DERECHO DE PROPIEDAD EN LA CONSTITUCIÓN DEL SIGLO XIX}

Tras casi cuarenta años de guerras civiles, Argentina sancionó en 1853 una constitución que -luego de fracasados intentos previos- tendría estabilidad. Se la considera un ejemplo del constitucionalismo liberal o clásico, modelado a partir de la ley suprema estadounidense de 1787 y redactado a partir de un proyecto elaborado por Juan Bautista Alberdi en $1852^{1}$.

Abramovich y Courtis consideran que en este paradigma clásico ${ }^{2}$ el mercado aparece como el mejor mecanismo para la producción y la distribución de bienes. Al Estado solo corresponde mantener el marco institucional para dar previsibilidad y seguridad en las transacciones, sin interferir en la autonomía contractual. Las personas disfrutan de igualdad formal. El derecho de propiedad tiene una importancia crucial, como vía para alcanzar la prosperidad del conjunto. La CA1853 dedicó dos artículos a proteger este derecho. El primero es el artículo 14, que consagra -entre otros derechos- el de "usar y disponer de su propiedad"; todos los derechos, ciertamente, solo pueden ejercerse dentro de las normas que los regulen sin alterarlos (CA, art. 28). Por otra parte, el art. 17 contiene previsiones más específicas: la propiedad es "inviolable" y nadie puede ser privado de ella sino por sentencia judicial o por vía de una expropiación fundada en razones de utilidad pública, previo pago de una indemnización ${ }^{3}$. A través de estas cláusulas, la CA buscaba dar garantias que atraigan inversiones extranjeras e inmigración, eje del proyecto agroexportador ${ }^{4}$ esbozado por $\mathrm{Alberdi}^{5}$ y puesto en marcha por la dirigencia que tomó el mando del país en la segunda mitad del siglo XIX ${ }^{6}$.

La formulación clásica del derecho de propiedad -sostenida también en

1 Véase Alberdi, Juan Bautista, Bases y puntos de partida para la organización politica de la República Argentina [1852], Centro Editor de América Latina, Buenos Aires, 1979.

2 Abramovich, Victor y Courtis, Christian, Los derechos sociales como derechos exigibles, Trotta, Madrid, 2002, pp. 50-52.

3 Incluso se reconocen efectos a la propiedad sobre personas: en el art. 15, la Constitución de 1853 establece una indemnización para los dueños de esclavos que resulten afectados por la abolición de este régimen.

4 Véase Rapoport, Mario et al., Historia económica, politica y social de la Argentina (1880-2000), Macchi, Buenos Aires, 2000, pp. 10-13.

5 Alberdi, Juan Bautista, Bases y puntos de partida para la organización politica de la República Argentina, op. cit., pp 60-65. El art. 25 de la CA establece que “el Gobierno federal fomentará la inmigración europea”; el art. 20 consagra la igualdad completa en derechos civiles para personas nativas y extranjeras.

${ }^{6}$ Oszlak, Oscar, La formación del estado argentino, Editorial de Belgrano, Buenos Aires, 1982. 
la legislación civil concordante ${ }^{7}$ - generó tensiones a partir del cambio de siglo. La desigual distribución de los bienes fue uno de los ejes de la denominada "cuestión social", esto es, el debate sobre el reparto del producido social. Poco más tarde, el derecho de propiedad también sufrió embates cuando el Estado necesitó ejercer de modo más amplio sus facultades regulatorias en los distintos sectores económicos ${ }^{8}$. La Corte Suprema argentina, desde 1922, comenzó a admitir limites a la libertad de contrato, particularmente en el ámbito de la locación de viviendas, aunque algunos votos en disidencia insistían en el carácter "amplísimo del derecho de propiedad, concebido según las ideas de Alberdi."9

A comienzos del siglo XX nuevas concepciones sobre el derecho de propiedad ganaron espacio en el debate público. Las distintas vertientes del socialismo impulsaban -y en algunos casos, implementaban- maneras distintas de reglamentar este derecho. Desde otra perspectiva, el jurista francés Léon Duguit que en 1911 brindó una recordada serie de conferencias en Buenos Airespropuso concebir a la propiedad como una "función social": siempre debe ser utilizada de modo productivo, en beneficio de la comunidad. El Estado tenía el deber permanente de actuar cuando esa función no se cumpliera. Esta teoria imponía obligaciones sobre la persona propietaria y, a la vez, sobre el Estado. La propuesta iba más allá del instituto de expropiación por utilidad pública, que tenía un carácter excepcional. Hacia mediados del siglo XX, la mayoría de las constituciones de América Latina habian incorporado la función social de la propiedad $^{10}$. El caso argentino se expone en el próximo apartado.

\section{1949: UN NUEVO CONSTITUCIONALISMO, UN NUEVO DERECHO DE PROPIEDAD}

Argentina se incorporó al campo del constitucionalismo social en 1949. Este nuevo modelo surge frente a los limites del constitucionalismo clásico para atender a la "cuestión social" planteada desde mediados del siglo XIX. La distinción entre Estado y ciudadano, eje de las constituciones clásicas, no permitía tratar otras diferencias sociales, como la existente entre la patronal y la población obrera. La igualdad de derecho o igualdad formal no alcanzaba a resolver la desigualdad económica ${ }^{11}$. Se desarrollaron nuevos derechos -

7 Ankersen, Thomas y Ruppert, Thomas, "Tierra y libertad: the social function doctrine and land reform in Latin America”, Tulane Environmental Law Journal, vol. 19, 2006, pág. 94.

8 Véase Cantón, Darío y Moreno, José Luis, “La experiencia radical (1916-1930)", en Cantón, Darío, Moreno, José Luis y Ciria, Alberto, Argentina. La democracia constitucional y su crisis, Paidós, Buenos Aires, 1980, pp. 21-52.

9 “Tanzi, Héctor José, "La Corte Suprema del individualismo liberal (1903-1930)", en Santiago, Alfonso (h) (director), Historia de la Corte Suprema argentina, Marcial Pons, Buenos Aires, 2013, tomo I, pp. 276-281."

10 Ankersen, Thomas y Ruppert, Thomas, "Tierra y libertad: the social function doctrine and land reform in Latin America", op. cit., pp. 95, 98-99, 107. Véase también Pasquale, Florencia, "La función social de la propiedad en la obra de Léon Duguit: una re-lectura desde la perspectiva historiográfica", Historia Constitucional, núm. 15, 2014, pp. 93-111; y Foster, Sheila R. y Bonilla, Daniel, "Symposium. The social function of property: a comparative law perspective. Introduction", Fordham Law Review, vol. 80, 2011, pp. 101-113.

11 Midón, Mario A. R., Manual de derecho constitucional argentino, Plus Ultra, Buenos Aires, 
especialmente en cabeza de los trabajadores- que se incorporaron a constituciones aprobadas desde comienzos del siglo $\mathrm{XX}^{12}$. Entre ellas pueden citarse las de México (Querétaro, 1917) y Alemania (Weimar, 1919), y más tarde las de la República Española (1931), Italia (1947) y Alemania Federal (1949), entre otras. Bajo un marco ideológico distinto, también puede incluirse la Constitución soviética de $1918^{13}$. Incluso Estados Unidos acusó el impacto: en su discurso sobre el estado de la Unión de 1944, el presidente Franklin D. Roosevelt propuso una "Segunda Declaración de Derechos", para dar cabida a los derechos sociales y complementar las diez primeras enmiendas aprobadas a fines del siglo XVIII. Roosevelt sostuvo que el objetivo para la posguerra no solo sería la seguridad física, sino también la seguridad económica, social y moral ${ }^{14}$.

Estos cambios forman parte de lo que Abramovich y Courtis denominan el paradigma del derecho social ${ }^{15}$. Consistía en una corrección del anterior ${ }^{16}, \mathrm{y}$ no en un modelo opuesto ${ }^{17}$ (salvo en el caso del constitucionalismo soviético). Admitía la necesidad de la intervención del Estado en el mercado, en el marco de una sociedad conflictiva; se podria utilizar el poder estatal para compensar las desigualdades. El derecho público comienza a regular ciertas áreas de la vida social para desmercantilizarlas: ya no sería el mercado el mecanismo exclusivo de distribución de ciertos bienes ${ }^{18}$. Se introdujeron limites a la autonomía de la voluntad contractual, especialmente en el plano laboral: ciertas condiciones minimas eran irrenunciables

1997, pág. 242.

12 Otros fijan el inicio de este movimiento a mediados del siglo XIX; véase Badeni, Gregorio, Instituciones de derecho constitucional, Ad Hoc, Buenos Aires, 1997, pág. 483.

13 La constitución soviética adoptaba objetivos ausentes en otras normas consideradas parte del constitucionalismo social. Por ejemplo: "la abolición de la explotación del hombre por el hombre, [...] [y] de la división del pueblo en clases, la supresión de los explotadores, el establecimiento de una sociedad socialista, y la victoria del socialismo en todos los países" (Art. 1, Cap. 2, p. 3); disponible en:

https://www.marxists.org/history/ussr/government/constitution/1918/index.htm

${ }^{14}$ Sunstein, Cass R., The second bill of rights. FDR's unfinished revolution and why we need it more than ever, Basic Books, Nueva York, 2004, pp. 2, 11.

15 Abramovich, Victor y Courtis, Christian, Los derechos sociales como derechos exigibles, op. cit., pp. 52-56. Una sintesis del contexto de surgimiento del entonces denominado "derecho social" o "derecho nuevo" -como rama que se proponía superar las versiones clásicas del derecho constitucional y del derecho civil- puede hallarse en Palacio, Juan Manuel, La justicia peronista. La construcción de un nuevo orden legal en la Argentina, Siglo XXI, Buenos Aires, 2018, pp. 34-55.

16 Así lo entiende, por ejemplo, Romero, para quien el constitucionalismo social busca un equilibrio entre individualismo y colectivismo, reconociendo al hombre en sus condiciones y necesidades concretas; véase Romero, César Enrique, Esbozo histórico del Estado y sus direcciones contemporáneas, Dirección General de Publicaciones de la Universidad Nacional de Córdoba, Córdoba, 1955, pp. 32-33.

17 Badeni, Gregorio, Instituciones de derecho constitucional, op. cit., pág. 484. En el mismo sentido, Vanossi, Jorge R., El Estado de Derecho en el constitucionalismo social, Eudeba, Buenos Aires, 1987, pág. 356.

18 Esping-Andersen, Gøsta, Los tres mundos del Estado de Bienestar, Alfons el Magnànim, Valencia, 1993. Lema Añón, por su parte, agrega que los derechos sociales abren también la vía para la producción de los bienes como salud, vivienda o educación de modos alternativos, que eviten su posterior conversión en mercancías. No se apuntó solo a la etapa de la distribución, sino también a la de producción; véase Lema Añón, Carlos, "Derechos sociales, ¿para quién? Sobre la universalidad de los derechos sociales”, Derechos y libertades, núm. 22, 2010, pp. 179-203. 
y las cláusulas abusivas se consideraban nulas ${ }^{19}$. Junto a la clásica libertad de trabajo se garantizaban protecciones especiales para el personal ${ }^{20}$. En lugar del Estado "gendarme", no intervencionista en el plano económico, se consolidó el denominado "Estado social de derecho", o "de bienestar"21.

Una versión del constitucionalismo social se concretó en el derecho argentino mediante la reforma de 1949, durante la primera presidencia de Juan Domingo Perón. En agosto de 1948, el Congreso argentino -a través de la ley 13.233- declaró la necesidad de la reforma. La aprobación generó polémicas, ya que -según algunos sectores- no se reunió la mayoría agravada exigida por el art. 30 de la CA. Ello sirvió de base para posteriores impugnaciones a la legitimidad del proceso ${ }^{22}$. El art. 1 de la ley 13.233 declaró la necesidad la "revisión y reforma de la Constitución nacional" para "la mejor defensa de los derechos del pueblo y del bienestar de la Nación": el alcance de la reforma sería amplio. La elección de convencionales constituyentes -en diciembre de 1948- dio el triunfo al gobernante Partido Peronista (o Justicialista): por la legislación electoral vigente desde $1912^{23}$, le correspondieron dos tercios de las bancas. La UCR, principal fuerza opositora, alcanzó el segundo lugar y obtuvo el tercio restante de escaños. Inaugurada en enero de 1949, la Convención sancionó el texto reformado el 11 de marzo de ese año. Hubo numerosos momentos de tensión durante las sesiones ${ }^{24}$ y finalmente, la UCR abandonó el Cuerpo tras presentar su despacho minoritario el 8 de marzo ${ }^{25}$. La mayoría peronista, con cuórum propio, continuó sesionando.

El justicialismo impulsó la inclusión de derechos sociales en la Constitución: el nuevo artículo 37 reconocía los derechos del trabajador, de la familia, de la ancianidad y de la educación y la cultura. En las intervenciones de los convencionales peronistas, la dignidad humana del trabajador, la justicia social y

19 Sagüés, Néstor P., Elementos de Derecho Constitucional, Astrea, Buenos Aires, 1999, tomo II, pág. 654; Ekmekdjian, Miguel A., Tratado de derecho constitucional, op. cit., tomo II, pág. 10.

20 Ekmekdjian, Miguel A., Tratado de derecho constitucional, op. cit., tomo II, pág. 9. Sin embargo, Badeni señala que es "un frecuente y grave error [...] creer que el constitucionalismo social aspira a proteger a los trabajadores frente a los empleadores"; este autor sostiene que el objetivo perseguido es la "coordinación armónica entre los intereses individuales y los intereses sociales”; véase Badeni, Gregorio, Instituciones de derecho constitucional, op. cit., pág. 484.

21 Ekmekdjian, Miguel A., Tratado de derecho constitucional, op. cit., tomo II, pág. 4; Vanossi, Jorge R., El Estado de Derecho en el constitucionalismo social, op. cit., pág. 357.

22 Dalla Vía señala que esta reforma estuvo "viciada de ilegitimidad de origen"; véase Dalla Vía, Alfredo, Derecho constitucional económico, LexisNexis, Buenos Aires, 2006, pág. 297.

23 Se trata del sistema que regía en el país desde 1912, con la aprobación de la ley 8871 o "Ley Sáenz Peña".

24 Una expresión de ello está en la intervención del convencional Sobral (UCR) al presentar su informe en minoría: "dentro de la vida argentina discurren [...] dos grandes corrientes; la autocrática [...] que justifica todas las dictaduras, y la otra, la de la libertad, de la democracia, la pura y limpia [...][H]an luchado aquí; pero estamos librando nosotros la batalla final. [...] Esta reforma es el enfrentamiento [...] de esas dos corrientes. Una de las dos tiene que sucumbir definitivamente [...]: la que ustedes representan o la que representamos y sentimos nosotros". Y poco más tarde agrega: "la Unión Cívica Radical [...] inicia la lucha y la proseguirá en cualquier forma [...]". Véase Diario de Sesiones de la Convención Nacional Constituyente. Año 1949, tomo I, Imprenta del Congreso de la Nación, Buenos Aires, 1949, pp. 306-307.

25 Ídem, pág. 339. 
la armonía entre patrones y obreros ${ }^{26}$, junto a la solidaridad y ciertos puntos del pensamiento católico ${ }^{27}$ aparecieron como bases principales de los derechos sociales, cuya consagración constitucional impediria que "un vaivén reaccionario, jurisprudencial o legislativo eche por tierra el edificio alzado sobre la base de la justicia social, so pretexto de cumplir las normas de la Constitución"28.

La base ideológica incluía una impugnación del liberalismo consagrado en la CA1853. El jurista Arturo Sampay, una de las voces principales en el bloque peronista, afirmó que "la reforma constitucional instaura un orden económico esencialmente anti-capitalista"; sin embargo, aclaró que la alternativa propuesta es rescatar el "espíritu económico precapitalista o tradicionalista", que Sampay describe como "la ética económica cristiana"29.

No se crearon vías judiciales -como la acción de amparo- para exigir los nuevos derechos sociales ${ }^{30}$. Un autor contemporáneo a la reforma señaló que la garantía genuina se hallaba en el modelo económico adoptado en la ley suprema ${ }^{31}$ : una politica económica intervencionista y nacionalista, que ahora se legitimaba más allá de toda duda ${ }^{32}$. Modificando el marco ideológico general ${ }^{33}$ heredado del siglo XIX, se subordinó el capital al bienestar social (art. 39) y se fijó la propiedad estatal sobre las fuentes de energia, los yacimientos y los servicios públicos (art. 40). Sampay explicaba que la nacionalización de las riquezas naturales y de los servicios públicos permitiría también utilizarlos como "instrumento de la reforma social"34. El modelo económico se mostraba como una garantía de los derechos de la población trabajadora.

${ }^{26} \mathrm{El}$ convencional justicialista Valenzuela, por ejemplo, afirmaba que se busca "reemplazar la economía capitalista de explotación, reemplazándola por una economía social en la que no haya explotadores ni explotados" (Diario de Sesiones de la Convención Nacional Constituyente. Año 1949, op. cit., pág. 320). El convencional peronista Espejo, entonces secretario general de la central sindical argentina, en el mismo sentido, planteaba que a partir de la reforma podrá haber patrones y obreros, pero no "zánganos" ni explotación (Ídem, pág. 385).

27 "La filosofia política del peronismo es sencillísima", afirmaba el convencional justicialista Carvajal: "[e]n su parte espiritual, está inspirada en la doctrina cristiana; en la parte moral, en nuestras tradiciones, en los valores inmutables de nuestra patria, y en la parte social pertenece pura y exclusivamente a Perón"; véase Diario de Sesiones de la Convención Nacional Constituyente. Año 1949, op. cit., pág. 391. Sampay cita la encíclica Quadragesimo Anno para fundar su exposición sobre la justicia social; ídem, pág. 278.

28 Diario de Sesiones de la Convención Nacional Constituyente. Año 1949, op. cit., pág. 273.

29 Ídem, pág. 279.

30 En cambio, sí se incorporó una garantía judicial explícita para la libertad ambulatoria: el art. 29 reformado incluía el hábeas corpus.

31 Antoni, Norberto, "Los derechos sociales en la Constitución Nacional argentina de 1949", en Valle, Adolfo, Subordinación y contrato de trabajo, s. e., Buenos Aires, 1950, pág. 39.

${ }^{32}$ Rapoport, Mario et al., Historia económica, politica y social de la Argentina (1880-2000), op. cit., pág. 358.

33 Ello puede observarse, también, en la modificación introducida al Preámbulo. Manteniendo el texto aprobado en 1853 e inspirado en el preámbulo de la Constitución estadounidense, la convención reformadora hizo dos adiciones. En primer lugar, luego de "promover el bienestar general", los constituyentes añadieron "y la cultura nacional". En segundo lugar, antes de la invocación a Dios, se agregó: "ratificando la irrevocable decisión de constituir una Nación socialmente justa, económicamente libre y politicamente soberana", un lema del justicialismo.

34 Diario de Sesiones de la Convención Nacional Constituyente. Año 1949, op. cit., pág. 282. 
En este marco de ideas, la función social de la propiedad privada quedó consagrada en al art. 3835. El texto se inicia con esta declaración: "La propiedad privada tiene ${ }^{36}$ una función social $\mathrm{y}$, en consecuencia, estará sometida a las obligaciones que establezca la ley con fines de bien común"37. Luego otorga al Estado la facultad de "fiscalizar la distribución y la utilización del campo", como así también "intervenir con el objeto de desarrollar e incrementar su rendimiento". Por último, el artículo encomienda al Estado "procurar a cada labriego o familia labriega la posibilidad de convertirse en propietario de la tierra que cultiva". Según Ramella, la reforma de 1949 prioriza a la producción y al sujeto productor por encima de la titularidad formal del dominio ${ }^{38}$. El resto del artículo transcribe las cláusulas adoptadas en el siglo XIX, que prohíben la confiscación y prevé la expropiación con indemnización previa. Además de la causal de "utilidad pública", la reforma de 1949 agregó la de "interés general"; ambas debian ser declaradas por ley.

Por otra parte, en la Convención el oficialismo hacía explícito su rechazo al comunismo, remarcando que se mantenía "intacto" el derecho de poseer privadamente y de heredar ${ }^{39}$. Sampay destacaba que la propiedad privada "es exigida por la libertad del hombre", aunque pocas frases más adelante señalaba que existe "solamente en razón de la utilidad que presta en la vida social" 40 . Es posible encontrar alguna contradicción entre estos fundamentos naturalistas y utilitaristas de la propiedad privada.

La versión final del art. 38 no incluía un pasaje contenido en el proyecto original presentado a la Convención por el bloque peronista: "Asimismo, se adoptarán las medidas necesarias para la extinción de los latifundios"41. Esto imponía al Estado la obligación de llevar adelante acciones positivas para el logro de ese objetivo. La Subcomisión de la Convención encargada de debatir el artículo

35 Se ha observado que incluso antes de la Reforma, la Corte Suprema designada durante la presidencia de Perón ya reconocía las limitaciones al derecho de propiedad; véase Abásolo, Ezequiel, "La Corte Suprema durante el régimen peronista (1947-1955)", en Santiago, Alfonso (h) (dir.), Historia de la Corte Suprema argentina, Marcial Pons, Buenos Aires, 2013, tomo II, pp. 481526.

36 Se utilizó el verbo "tiene" en lugar de "es". Esta segunda fórmula pertenecía a Léon Duguit, y no convenció al justicialismo porque podría acarrear la suspensión completa de la propiedad privada; véase Ramella, Susana, "Propiedad en función social en la Constitución de 1949. Una 'mentalidad' del Antiguo Régimen representada en el constitucionalismo social de la época", Revista de Historia del Derecho, núm. 35, 2007, pág. 302.

37 En este artículo Sampay encontraba las bases para un nuevo Código Civil; véase Ramella, Susana, "Propiedad en función social en la Constitución de 1949. Una 'mentalidad' del Antiguo Régimen representada en el constitucionalismo social de la época”, op. cit., núm. 35, 2007, pág. 304.

38 Ramella, Susana, "Propiedad en función social en la Constitución de 1949. Una 'mentalidad' del Antiguo Régimen representada en el constitucionalismo social de la época”, op. cit., pág. 304.

39 Intervención del convencional peronista Valenzuela, Diario de Sesiones de la Convención Nacional Constituyente. Año 1949, op. cit., pág. 322. Desde la oposición, el convencional Sobral (UCR) denunciaba que la reforma no avanzaba en la socialización de los bienes ni en el control de la producción, ni proponía una "revisión paulatina del sistema capitalista", por lo que la juzgaba inocua; idem, pp. 608-610.

40 Diario de Sesiones de la Convención Nacional Constituyente. Año 1949, op. cit., pág. 277.

41 Ídem, pág. 34. 
sobre propiedad introdujo cambios en el proyecto. Primero (en la reunión del 9 de febrero de 1949), reemplazó -a propuesta del convencional peronista Caesar- la expresión citada por esta otra: "Los latifundios serán racionalmente fraccionados, facilitando el desarrollo de la pequeña propiedad agrícola"42. Esta nueva versión no aclara quién fraccionará las grandes extensiones, ni fija obligaciones en ese sentido. Tampoco resulta clara la conexión entre esa posible división y la pequeña propiedad que se pretende estimular: ¿acaso se repartirán las fracciones? ¿Deben ser esas fracciones de reducida extensión? La incertidumbre aumenta cuando el acta de la reunión consigna que la noción de latifundio es "relativa y sujeta a factores de población, riqueza del suelo, medios de comunicación, etcétera". Dos días después, el mismo convencional Caesar manifestó en la Subcomisión que por "la trascendencia de la labor que cumplian", él necesitaba "reflexionar nuevamente" sobre lo acordado en las deliberaciones anteriores; el resto del bloque oficialista adhirió a este pedido ${ }^{43}$. Finalmente, en la reunión del 17 de febrero se eliminó la referencia a los latifundios, a su extinción o a su fraccionamiento ${ }^{44}$. En su lugar, se facultaba al Estado -como ya vimos- a "controlar la repartición y la utilización del campo". No hay una política activa contra los latifundios. Este vocablo pasó al inciso 16 del art. 68 reformado; allí se incluyó como una de las facultades del Congreso "promover [...] la colonización de tierras de propiedad nacional y de las provenientes de la extinción de latifundios, procurando el desarrollo de la pequeña propiedad agrícola [...]". Como se ve, en este pasaje la extinción de los latifundios es una circunstancia, un hecho cuyo origen no se explicita. Se fija al Congreso una tarea (promover colonización de tierras) luego de que se extingan los latifundios; esto último no es responsabilidad del Legislativo (o de otro poder público). Así quedó consagrado en el segundo proyecto del Partido Peronista ${ }^{45}$.

La función social de la propiedad consagrada en el art. 38 no apuntaba ya a extinguir los latifundios, sino a justificar las obligaciones impuestas a la propiedad -sobre cualquier bien- con fines de bien común. El latifundio podria continuar existiendo, aunque sujeto a estos deberes y bajo control del Estado sobre su utilización.

De todas formas, el convencional Sampay intentó retomar en sus intervenciones el programa para la erradicación del latifundio. Sostenía que el artículo 38 en su redacción final permitiría al Estado "expropiar sus tierras a quienes no las hacen rendir por abandono, desidia o incapacidad" y "distribu[irlas] entre los aptos para trabajarlas como propietarios"; agregaba que debían "crearse las condiciones económicas que permitan el ejercicio efectivo del derecho natural a ser propietario" 46 . En esta intervención podemos ver, por una parte, la visión jusnaturalista sobre el derecho de propiedad, junto a la preocupación por el uso productivo de la tierra; por otra, el objetivo de multiplicar el número de propietarios como vía para superar las desigualdades que la CA1853 había permitido. Es quizá un punto de encuentro entre la ética cristiana precapitalista y el constitucionalismo social de posguerra.

\footnotetext{
42 Ídem, pág. 613.

43 Ídem, pág. 615.

44 Ídem, pág. 623.

45 Ídem, pág. 250.

46 Ídem, pág. 278.
} 


\section{1957: UNA REFORMA QUE NO ALCANZÓ AL DERECHO DE PROPIEDAD}

Un golpe de Estado derrocó en 1955 al gobierno de Juan Perón. La dictadura militar surgida de ese golpe derogó por proclama ${ }^{47}$ la CA1949 y repuso la CA1853. También declaró ilegal -mediante el decreto 4161/195648 - al Partido Peronista e incluso la mención pública del nombre del presidente depuesto. Poco después, la dictadura convocó a un nuevo proceso de reforma, sin cumplir los requisitos fijados en el art. 30 de la $\mathrm{CA}^{49}$ : el Congreso, encargado de declarar por mayorias agravadas la necesidad de la reforma, estaba disuelto desde el golpe. Por lo tanto, el llamado a convención se hizo mediante un decreto presidencial ${ }^{50}$. Pese a estos vicios formales de origen ${ }^{51}$, sus aportes al texto constitucional han quedado consagrados, más allá de las dificultades en su implementación ${ }^{52}$.

Las elecciones de convencionales constituyentes se llevaron a cabo en julio de 1957. Pocos meses antes, la UCR se había dividido ${ }^{53}$. El ala más cercana al gobierno militar reconoció como líder a Ricardo Balbín y se denominó UCR del Pueblo (UCRP). En torno a Arturo Frondizi se agruparon dirigentes dispuestos a acordar con el peronismo para alcanzar la Presidencia: adoptaron el nombre de UCR Intransigente (UCRI). Estos dos nuevos partidos concurrieron a las elecciones de convencionales. Por su parte, el ilegalizado Partido Peronista no pudo presentar candidaturas y resolvió abstenerse. En los comicios se registró un $24,3 \%$ de votos en blanco, porcentaje superior a los obtenidos por la UCRP y la UCRI, los dos partidos más votados $^{54}$. Hay quienes describen a la elección de 1957 como una "encuesta encubierta" 55 sobre el electorado, por parte del sector que buscaba la continuidad del gobierno militar en una presidencia de Balbín, líder de la UCRP56. En esta

47 La proclama se dictó el 27 de abril de 1956; véase Sagüés, Néstor P., Elementos de Derecho Constitucional, op. cit., tomo I, pág. 219.

48 Emitido el 5 de marzo de 1956; véase Rodríguez Lamas, Daniel, La Revolución Libertadora, Centro Editor de América Latina, Buenos Aires, 1985, pp. 71-72.

49 Quiroga Lavié, Humberto, Constitución de la Nación Argentina. Comentada, Zavalía, Buenos Aires, 2000, pág. 82 .

50 Dec. 3838, del 12 de abril de 1957.

51 Reconocidos en Gelli, María Angélica, Constitución de la Nación Argentina.Comentada y concordada, 3a edición, La Ley, Buenos Aires, 2005, pág. 153; según esta autora, esos vicios de origen se saldaron con el proceso de reforma de 1994; la misma postura en Dalla Vía, Alfredo, Derecho constitucional económico, op. cit., pág. 298 y en Quiroga Lavié, Humberto, Constitución de la Nación Argentina. Comentada, op. cit., pág. 82.

52 Gelli señala que se fue convirtiendo en una "formulación normativa cada vez más ajena a la realidad", véase Gelli, María Angélica, Constitución de la Nación Argentina. Comentada y concordada, op. cit., pág. 155.

53 Rodríguez Lamas, Daniel, La Revolución Libertadora, op. cit., pp. 86-87; Serafin, Albino, 1955. Revolución Libertadora. Gobierno y partido de la UCRI en Córdoba, Narvaja Editor, Córdoba, 1994, pp. 43-50.

54 UCRP: 24,2\%; UCRI 21,2\%; véase Rodríguez Lamas, Daniel, La Revolución Libertadora, op. cit., pp. 90-91.

55 Odena, Isidoro J., Libertadores y desarrollistas 1955-1962, La Bastilla, Buenos Aires, 1988, pág. 76.

56 Rouquié, Alain, Poder militar y sociedad politica en la Argentina. 1943-1973, Emecé, Buenos Aires, 1982, pp. 143-144. 
ocasión se aplicó el sistema de representación proporcional ${ }^{57}$, por lo que varios partidos tuvieron presencia en la Convención. Pese a haber alcanzado el segundo lugar en votos, la UCRI tenía el número más alto de convencionales electos (77). La UCRP, con unos 250.000 sufragios más, obtuvo 75 escaños $^{58}$.

La Convención reformadora sesionó en Santa Fe desde el 30 de agosto, y concluyó antes de lo previsto el 14 de noviembre de $1957^{59}$. Los convencionales electos por la UCRI asistieron a la primera sesión preparatoria, pero solo para denunciar la ilegitimidad del Cuerpo; luego se retiraron sin prestar juramento ni asumir las bancas ${ }^{60}$. Tampoco se integraron a la Convención otros tres representantes de partidos menores cercanos al proscripto justicialismo. La UCRP contó con el bloque más numeroso. Se ha señalado que durante los debates la UCRP -cercana al gobierno militar- impulsó propuestas destinadas a captar al electorado peronista; en tanto, la UCRI se postulaba como expresión del voto en blanco, anticipando el acuerdo que meses más tarde celebraría con el exiliado líder del justicialismo61.

El resto del Cuerpo se integró con 12 convencionales del Partido Socialista, 8 del Partido Demócrata Cristiano, 7 del llamado Bloque del Centro (alianza de partidos conservadores de distintas provincias), 5 del Partido Demócrata Progresista, 3 del Partido Comunista y 7 de otras agrupaciones menores.

El saldo de la Convención consistió, centralmente, en la incorporación de un nuevo artículo en la CA: el 14 bis, que en tres párrafos reconoce los derechos de las personas que trabajan y de los gremios, y regula la seguridad social. Por supuesto, la redacción es diferente a la de 1949; una de las más visibles innovaciones fue incorporar el derecho a huelga, excluido en la reforma peronista. Así, bajo una formulación distinta, los derechos sociales se incorporaron nuevamente ${ }^{62}$, conviviendo con el resto del texto del siglo XIX, que no sufrió modificaciones 63 .

No se agotaba allí el amplio temario previsto para la Convención. El decreto de convocatoria incluía el régimen electoral, el sistema federal de gobierno, el equilibrio entre los poderes, las autonomias municipales, la libertad individual, y el dominio y explotación de fuentes naturales de energía. Nada de eso pudo tratarse porque a mediados de noviembre un grupo de convencionales (principalmente del Bloque del Centro) abandonó la Convención y la privó del cuórum $^{64}$. Mediante una declaración pública ${ }^{65}$, denunciaron el peligro de avanzar

57 Decreto 3838/57, art. 7 .

58 Esto obedecía a la aplicación del sistema proporcional, que podía favorecer a los partidos que vencían en distritos menos poblados.

59 Sagüés, Néstor P., Elementos de Derecho Constitucional, op. cit., tomo I, pág. 220.

60 Véase Diario de Sesiones de la Convención Nacional Constituyente. Año 1957, Imprenta del Congreso de la Nación, Buenos Aires, 1958, tomo I, pp. 3-7.

61 Rapoport, Mario et al., Historia económica, politica y social de la Argentina (1880-2000), op. cit., pág. 500.

62 Sagüés, Néstor P., Elementos de Derecho Constitucional, op. cit., tomo I, pág. 249.

63 En rigor, sí hubo un cambio más: se incorporó entre las atribuciones del Congreso federal la de dictar un Código del Trabajo y la Seguridad Social (análogo en su función a los códigos Civil, Penal o Comercial). Todavía hoy el Congreso no ha ejercido esa facultad.

64 Sagüés, Néstor P., Elementos de Derecho Constitucional, op. cit., tomo I, pág. 220; Diario de 
en "la reforma agraria", "la estatización de la economía privada" y "el monopolio oficial de los servicios públicos", entre otras modificaciones impulsadas por la UCRP y bloques menores, mostrando "una peligrosa orientación de colectivismo de izquierda que contrarian nuestro derecho y que este país no quiere". Más aún: recuperar el modelo económico de la CA1949 significaría "reincidir en un ensayo totalitario", y también "la rehabilitación histórica del gobierno depuesto" (el de Juan Perón).

La función social de la propiedad, efectivamente, estuvo en el temario de la Convención. Hubo distintos proyectos; su tratamiento quedó impedido por la retirada del grupo conservador. Desde el punto de vista formal, las distintas propuestas se planteaban como cambios en la cláusula que reconoce a cada persona -desde 1853- el derecho "de usar y disponer de su propiedad". El despacho de mayoría elaborado por la UCRP66 junto a otros bloques menores agregaba, luego de esas palabras: "El ejercicio de este derecho está condicionado por la función social que desempeña la propiedad". También ordenaba asegurar "el más amplio acceso a la propiedad". El Estado quedaría a cargo de "promove[r] la división de latifundios" y entregar la tierra pública de propiedad nacional en "concesiones vitalicias hereditarias" equivalentes a unidades económicas definidas por ley y sujetas al pago de un canon periódico.

Esta propuesta comparte con el art. 38 aprobado en 1949 el reconocimiento de la función social que "tiene" (1949) o "desempeña" (1957) la propiedad. El despacho de 1957 parece avanzar más al poner al Estado a cargo de impulsar la división de latifundios, retomando el texto que la Subcomisión de 1949 decidió eliminar. El proyecto de 1957 también impulsa la ampliación del conjunto de propietarios sin distinciones geográficas, mientras que el artículo de 1949 se centraba en las "familias labriegas" (esto es, en el ámbito rural). Por último, la propuesta de 1957 reemplazaba la entrega en propiedad por un sistema de concesiones, mientras que el Estado retenía la titularidad del dominio sobre sus tierras; la CA1949, en cambio, fomentaba la "pequeña propiedad agraria" (énfasis añadido).

A la vez, el despacho impulsado por la UCRP y bloques convergentes incluía dos nuevos artículos que parecían resucitar el modelo económico de la reforma justicialista. El primer artículo reconocia el valor de la iniciativa privada, "siempre que no tenga por fin ostensible o encubierto dominar los mercados nacionales, disminuir la libre competencia o aumentar usurariamente los beneficios": las palabras coinciden textualmente con el art. 40 de la CA1949. También establecía la propiedad estatal sobre los servicios públicos y limitaba la posibilidad de concesión. El segundo artículo propuesto declaraba como propiedad "imprescriptible e inalienable de la Nación" a las fuentes naturales de energía, cuya explotación correspondia exclusivamente al Gobierno federal. Se preveian, además, las pautas para compensar por eventuales expropiaciones.

Al presentar el despacho de mayoría, el convencional Ricardo Fuertes (UCRP) destacó que la propiedad "tiene" (y no "es") una función social: "el fundamento de la propiedad es inseparable de su utilización”, de su finalidad "individual y social a la

Sesiones de la Convención Nacional Constituyente. Año 1957, op. cit., tomo II, pp. 1552 y ss.

65 Incluida en el Diario de Sesiones de la Convención Nacional Constituyente. Año 1957, op. cit., tomo II, pág. 1604.

66 Ídem, pp.1017-1019. 
vez", lo que implica "el respeto del derecho de propiedad privada y el control de su ejercicio por el poder político, intérprete del interés social". Agregaba que esta nueva formulación del derecho de propiedad permitiría defenderlo del colectivismo. La expropiación -por "utilidad pública" o por las nuevas causales de "interés social" y "bienestar general"- era una medida de autodefensa de la sociedad67. Otro convencional de la UCRP, Ricardo Lavalle, explicaba que la función social de la propiedad "significa, precisamente, condicionar el uso y disfrute de la misma a los intereses superiores de la comunidad"; advertía que de ninguna forma representaba un giro colectivista, " $\mathrm{y}$ mucho menos, todavia, transplantar instituciones del régimen soviético"68. Adolfo Rouzaut, también integrante de la UCRP, comparaba a los latifundios con los feudos 69 : aquí puede inferirse que el objetivo era adaptar la propiedad argentina a la etapa capitalista, y no al socialismo.

El Partido Comunista, precisamente, había presentado un proyecto propio ${ }^{70}$. Establecia que "la tierra tiene función social" y ordenaba expropiar los latifundios sin indemnización para repartirlos entre la población trabajadora extendiéndole títulos de propiedad. En caso de que razones económicas aconsejaran no dividir una superficie, se explotaría colectivamente por el Estado. También se promovería la formación de cooperativas. Por una parte, este planteo va más allá del despacho mayoritario en cuanto adopta el objetivo de terminar con los latifundios y excluye la indemnización. Por otra, su alcance es más acotado, porque parece limitarse a la propiedad rural.

La Democracia Cristiana presentó un proyecto mucho más limitado ${ }^{71}$ : definía a la tierra "como un bien de trabajo" y encomendaba al Estado la promoción de la "reforma agraria" fundada en la colonización de la tierra pública, sin definir acciones frente a la gran propiedad rural ${ }^{72}$. El despacho del Partido Demócrata Progresista sí contemplaba expropiaciones de tierras e inducir, por vía de impuestos, la división de los latifundios ${ }^{73}$. Yendo hacia la derecha del espectro político, el liberal Partido Cívico Independiente ${ }^{74}$ proponía "extender" el derecho de propiedad "al mayor número de habitantes"75. Por último, el bloque conservador -que finalmente abandonaría la Convención- proponía dejar la redacción de 1853 sin cambios, asegurando el derecho "de usar y disponer" de la propiedad, sin limitaciones particulares ${ }^{76}$.

${ }^{67}$ Ídem, pp. 1530-1535.

68 Ídem, pág. 1063.

69 Ídem, pág. 1068.

70 Ídem, pág. 853.

71 Ídem, pág. 1024.

72 El convencional José Antonio Allende, de la Democracia Cristiana, consideraba que el Código Civil vigente, aprobado en 1871, regulaba la propiedad en un sentido contrario a la visión cristiana; véase Diario de Sesiones de la Convención Nacional Constituyente. Año 1957, op. cit., pág. 1142 .

73 Ídem, pág. 1034.

${ }^{74}$ Mansilla, César L., Las fuerzas de Centro, Centro Editor de América Latina, Buenos Aires, 1983, pp. 133-135.

75 Diario de Sesiones - Convención 1957: II, 1039.

76 Ídem, pág. 1043. 
Puede concluirse que la opinión mayoritaria en la Convención de 1957 compartida por distintos bloques- era que el derecho de propiedad merecía una regulación especial, diferente a la que se daba a otros derechos. Se trataba de imponerle límites específicos, fundados en el interés social o el bien común. Algunos proyectos establecian pautas determinadas para el caso del latifundio, en tanto gran propiedad agraria, por su importancia en la economia argentina. A diferencia de 1949, esta vez el despacho mayoritario adoptaba el objetivo de promover la división de estas extensiones. Otros planteos más moderados simplemente impulsaban el reparto de tierras fiscales, sin afectar las propiedades ya existentes, o apenas fomentar que hubiera más familias propietarias.

La posición mayoritaria representaba un giro de fondo frente al esquema del siglo XIX. Rechazando explícitamente el modelo comunista, el proyecto sostenido por la UCRP consolidaba en la Constitución una economía con un rol estatal intervencionista y abría un cauce para revertir la histórica concentración de tierras (y el poder político y económico que ello confería al sector terrateniente) ${ }^{77}$. Esta posibilidad explica el retiro del sector conservador, un hecho que dejó sin cuórum a la Convención e impidió la aprobación de la propuesta mayoritaria. A partir de entonces, el derecho constitucional de propiedad mantuvo su fórmula de 1853; continuaría siendo -con mayor o menor éxito- un argumento jurídico contra distintas formas de regulación estatal en la economia.

\section{1994: NUEVAS PAUTAS PARA EL DERECHO DE PROPIEDAD}

Tras casi ocho años de dictadura militar, Argentina retomó la vigencia de sus instituciones democráticas a fines de 1983, bajo el imperio de la Constitución aprobada en 1853 y reformada por última vez en 1957. La reforma constitucional volvió a aparecer en el temario de la discusión política general ${ }^{78}$, como parte de un proyecto más amplio de renovación institucional impulsado por el presidente Raúl Alfonsín, dirigente de la UCR ${ }^{79}$. Alfonsín creó el Consejo para la Consolidación de la Democracia, integrado por dirigentes e intelectuales de distintas vertientes políticas ( $\sin$ incluir al comunismo ni a la derecha extrema). Este Consejo produjo en 1986 un dictamen sobre posibles modificaciones a la Constitución: incluía entre ellas la consagración de la función social de la propiedad, siguiendo el modelo de la Constitución alemana y de algunas constituciones provinciales argentinas. De esa forma podría lograrse "una distribución equitativa de la autonomia" y "evitar que se potencie la desigualdad de oportunidades"80. En el justicialismo, por su parte, muchos sectores

77 Véase De Imaz, José Luis, Los que mandan, Eudeba, Buenos Aires, 1964, pp. 106-125; y también Sandler, Héctor, "Reflexiones para un estudio crítico del derecho civil", Liberación y Derecho, núm. 1, pp 169-195, 1974.

78 Unamuno, Miguel y Bortnik, Rubén, La reforma constitucional en el siglo XX, Centro Editor de América Latina, Buenos Aires, 1986, pp. 43-47.

79 Véase Aboy Carlés, Gerardo, "Raúl Alfonsín y la fundación de la 'segunda república'”, en Gargarella, Roberto, Murillo, Maria Victoria y Pecheny, Mario (comp.), Discutir Alfonsin, Siglo XXI, Buenos Aires, 2010, pp. 71-74.

80 Consejo para la Consolidación de la Democracia, Reforma Constitucional. Dictamen preliminar del Consejo para la Consolidación de la Democracia, Eudeba, Buenos Aires, 1986, pp. 43-44. 
mantenían entonces su vocación reformista, alimentada por la experiencia de 1949.

Las urgencias de la crisis económica impidieron avanzar en los cambios constitucionales. El peronista Carlos Menem sucedió a Alfonsín en 1989 e implementó -con el apoyo de sectores políticos liberales- un amplio programa de privatización y desregulaciones. Luego de triunfar en dos elecciones parlamentarias, el justicialismo impulsó abiertamente la reforma de la Constitución para habilitar la reelección presidencial, prohibida en el texto de 1853. La opositora UCR rechazaba esa posibilidad. Finalmente un acuerdo entre Alfonsín y Menem permitió la sanción de la ley 24.30981 que declaraba la necesidad de la reforma y establecía un singular mecanismo para llevarla a cabo $^{82}$. Un grupo de cambios -denominados "Núcleo de Coincidencias Básicas"deberian adoptarse o desecharse en conjunto (art. 2). Por ejemplo, la posibilidad de reelección presidencial no podía sancionarse (o rechazarse) sin el acortamiento del mandato de seis a cuatro años. Aceptar cualquier punto del Núcleo significaría, automáticamente, aprobar todos los otros (art. 5). Por otra parte, la ley establecía una lista de "Temas Habilitados" (art. 3) que sí podian tratarse separadamente. Se fijaba, además, un importante límite a la Convención: no podria modificar ninguno de los primeros 35 artículos de la Constitución (art. 7): allí estaban todas las declaraciones y derechos adoptadas en 1853, 1860 y 1957. Esta restricción buscaba dar tranquilidad al ala liberal del gobierno, asegurando por ejemplo- que no se modificaría la versión decimonónica del derecho de propiedad consagrada en el art. 17 de la CA1853. El recuerdo de 1949 y 1957 exigía esta garantía para que el liberalismo aceptara acompañar la reforma. La ley 24.309 establecía la nulidad de cualquier reforma hecha en violación de estos estrictos limites (art. 6). La derecha tradicional y el gran empresariado desconfiaban del proceso reformista; temian que la agitación politica demorara los cambios económicos pendientes o fortaleciera a las centrales sindicales ${ }^{83}$.

Se eligieron 305 convencionales en abril de 1994. El oficialismo justicialista obtuvo la primera minoría y la UCR, 74 escaños. De esta forma, el cumplimiento del acuerdo reformista necesitaría de ambas fuerzas. El Frente Grande, una agrupación de centroizquierda enfrentada al Gobierno y al acuerdo entre Alfonsín y Menem, logró 31 bancas, frente a 28 de partidos de derecha dirigidos por militares retirados. El resto de los partidos reunía menos de una decena de escaños en conjunto ${ }^{84}$.

La convención sesionó en Santa Fe y Paraná entre el 25 de mayo y el 22 de agosto de 1994. Llevó adelante una reforma de amplio alcance; en algunos

81 Para más detalles del trámite, véase Alice, Beatriz L., "Acercimiento de derechos y garantías y creación de órganos de control en la reforma constitucional de 1994", en Ekmekdjian, Miguel Ángel y Ferreyra, Raúl Gustavo (coord.), La reforma constitucional de 1994 y su influencia en el sistema republicano y democrático, Depalma, Buenos Aires, 2000, pp. 36-37.

82 Véase Lhöest, Brigitte F. P., "Constitutional reform in Argentina", Verfassung und Recht in Übersee / Law and Politics in Africa, Asia and Latin America, vol. 28, núm. 2, 1995, pp. $155-165$.

83 Palermo, Vicente y Novaro, Marcos. Politica y poder en el gobierno de Menem. Norma, Buenos Aires, 1996, pp. 406-407.

84 Los datos referidos a la elección de 1994, disponibles en:

http://www.mininterior.gov.ar/asuntos_politicos_y_alectorales/dine/infogral/RESULTADOS\% 20HISTORICOS/1994.pdf 
aspectos adoptó cláusulas propias del constitucionalismo social y compatibles con un Estado intervencionista, mientras el Gobierno buscaba reducir el gasto público y consolidar la privatización de empresas públicas y del sistema previsional ${ }^{85}$. El presidente Menem, preocupado por este giro de la Convención, la instó a mantenerse dentro del acuerdo previo, para no afectar el plan económico vigente; el llamado fue reiterado por instituciones patronales ${ }^{86}$. A lo largo de la Convención, la prensa reflejó frecuentemente la tensión entre el ministro de Economía y las bancadas reunidas en Santa $\mathrm{Fe}^{87}$. Se ha sostenido que la reforma de 1994 modificó profundamente el marco ideológico de la Constitución ${ }^{88}$.

Entre las reformas introducidas, se destaca el inciso 22 del art. 75. Alli se otorga jerarquía constitucional a un listado de convenios internacionales y regionales de derechos humanos, tales como la Declaración Universal de Derechos Humanos (DUDH), la Declaración Americana de Derechos y Deberes del Hombre (DADDH), el Pacto de Derechos Civiles y Políticos (PDCP), el Pacto de Derechos Económicos, Sociales y Culturales (PDESC) y la Convención Americana de Derechos Humanos (CADH). También se habilitó ampliar ese listado en el futuro mediante la aprobación de mayorías legislativas agravadas. El nuevo inciso del art. 75 reconoce a estos tratados "en las condiciones de su vigencia": para su interpretación deben tomarse en cuenta las reservas formuladas por Argentina al tiempo de ratificación y las diferentes decisiones emitidas por los organismos de monitoreo de cada tratado 89 . El conjunto normativo integrado por el articulado de la CA y los tratados de igual jerarquía constituyen lo que la doctrina constitucional argentina denomina -mayoritariamente- el "bloque constitucional"90.

El derecho de propiedad no estaba dentro del temario de la Convención. Precisamente, el acuerdo político buscó aislarlo de la reforma mediante la prohibición de alterar los primeros 35 artículos de la Constitución ${ }^{91}$. Sin

85 Rapoport, Mario et al., Historia económica, social y politica de la Argentina (1880-2000), op. cit., pág. 973.

86 E1 Presidente pidió expresamente que "no se entre en el terreno del mamarracho" (La Nación, 6 de agosto de 1994). En una solicitada titulada "La responsabilidad de los constituyentes. Un llamado a la reflexión", la Bolsa de Comercio de Buenos Aires denuncia que las iniciativas de la Convención en el plano económico "son de tal gravedad, que de merecer aprobación [...] frustrarian la transformación económica que tantos esfuerzos ha requerido y aún requiere del pueblo argentino" (La Nación, 7 de agosto de 1994). Un comunicado similar emitió la Unión Industrial de Córdoba (La Voz del Interior, 11 de agosto de 1994).

87 Domingo Cavallo, ministro de Economía, declaraba: "Nosotros les hacemos llegar a los constituyentes nuestra opinión [sobre] [...] las consecuencias de lo que se aprueba" en la Convención ( $\mathrm{La} \mathrm{Voz} \mathrm{del} \mathrm{Interior,} 5$ de agosto de 1994).

88 Cayuso sostiene que se profundizó el carácter social del Estado de derecho; véase Cayuso, Susana, Constitución de la Nación Argentina: claves para el estudio inicial de la norma fundamental, La Ley, Buenos Aires, 2006, pág. 7. Véase también Gil Domínguez, 2009: 41-42. Sin embargo, no se modificó el Preámbulo ni el articulado de la primera, por lo que otros autores señalan el mantenimiento de un tinte "conservador liberal"; véase Pérez Hualde, 2000: 91, 112.

89 Gelli, María Angélica, Constitución de la Nación Argentina.Comentada y concordada, op. cit., pp. 712-713; Sagüés, Néstor P., Elementos de Derecho Constitucional, op. cit., tomo II, pp. 279280; Quiroga Lavié, Humberto, Constitución de la Nación Argentina. Comentada, op. cit., pág. 483.

90 Bidart Campos, Germán J., Tratado elemental del derecho constitucional argentino (vol. I-A), Ediar, Buenos Aires, 2000.

91 En el mismo periodo, algunos países como Perú y México eliminaron o debilitaron la noción 
embargo, nuevos textos sobre propiedad ganaron jerarquía constitucional: se trata de cláusulas contenidas en algunos de los tratados de derechos humanos mencionados en el art. 75 inc. 22. La interpretación sistemática de la CA exige leer en conjunto estos nuevos preceptos con los artículos 14 y 17, garantes de la propiedad desde 1853. Las cláusulas con rango constitucional no pueden destruirse, ni una prevalecer sobre la otra; de lo contrario, la hermeneútica violaría el principio de no contradicción. Sagüés define a este principio de sistematicidad como una de las áreas "pacificadas" del debate sobre interpretación ${ }^{92}$. La Convención de 1994 consideró que la CA y los tratados de igual jerarquía son compatibles entre sí; por lo tanto, la interpretación debe conducir a armonizar las cláusulas que parezcan contradecirse $\mathrm{e}^{93}$.

El art. 21 de la CADH prescribe que el "uso y goce" de los bienes puede "subordinar[se] [...] al interés social". De esta forma, algunas facultades del propietario quedan limitadas por necesidades de la comunidad, siguiendo el planteo propio del constitucionalismo social y recordando las lineas centrales de la reforma de 1949 y los proyectos de 1957. No se usa la expresión "función social", pero la noción de "interés social" puede cumplir un rol similar.

En segundo lugar, el art. 23 de la DADDH introduce una distinción en la protección debida al derecho de propiedad: "Toda persona tiene derecho a la propiedad privada correspondiente a las necesidades esenciales de una vida decorosa, que contribuya a mantener la dignidad de la persona y del hogar". Este artículo redefine el alcance del derecho humano de propiedad. No incluye toda clase de bienes, ni tampoco cualquier cantidad de ellos. El eje se halla en los elementos que satisfacen "necesidades esenciales de una vida decorosa" a fin de sostener la dignidad personal.

¿Cómo podría hacerse, entonces, una lectura sistemática del derecho de propiedad que armonice los arts. 14 y 17, expresión del liberalismo clásico vigente en 1853, con las pautas del siglo XX incorporadas en 1994? Es dificil conjugar ideas decimonónicas con el marco ideológico de la segunda posguerra. Pero solo nos cabe la tarea de encontrar una interpretación que permita la vigencia simultánea de todos estos textos dotados de la misma jerarquía.

Veamos una posible interpretación integradora. El derecho de propiedad en sí mantiene su carácter "inviolable" (CA, 17). Solo por excepción puede privarse a alguien de él, y siempre cumpliendo el procedimiento específico (expropiación por ley previamente indemnizada o bien sentencia judicial). El derecho de propiedad incluye el uso, goce y disposición según la reglamentación razonable (así ocurre con todos los derechos). Pero ahora se agrega un criterio adicional y específico para la regulación de este derecho: el "interés social".

de función social de la propiedad en sus constituciones; véase Ankersen, Thomas y Ruppert, Thomas, "Tierra y libertad: the social function doctrine and land reform in Latin America", op. cit., pp. 114-117.

92 Sagüés, Néstor P., Elementos de Derecho Constitucional, op. cit., tomo I, pág. 61.

93 Gelli, María Angélica, Constitución de la Nación Argentina.Comentada y concordada, op. cit., pág. 716; según la autora, esta postura es la mayoritaria en la Corte Suprema; la misma noción en Cayuso, Susana, Constitución de la Nación Argentina: claves para el estudio inicial de la norma fundamental, op. cit., pág. 266. 
Además, el tipo de bienes en cuestión tiene relevancia. Hay un conjunto de objetos cuyo uso, goce y disposición no puede subordinarse al interés social. Se trata de los "bienes esenciales" para defender la dignidad de la persona y el hogar. La especial referencia contenida en el art. 23 de la DADDH justifica darles un trato diferenciado.

Vemos así una nueva formulación de la facultad estatal regulatoria del derecho de propiedad. Se puede reglamentar con mayor amplitud que a otros derechos, incluso empleando un criterio específico con preeminencia (el interés social), salvo que se trate de bienes que satisfacen necesidades esenciales de una vida decorosa o mantienen la dignidad. Bajo este planteo, se pueden imponer más límites al uso y goce de grandes extensiones de tierra fértil, plantas industriales, o fuentes de energía. Pero no puede quitarse la propiedad sobre tales bienes, por la inviolabilidad de este derecho. Por otro lado, si se trata de los ahorros o la vivienda familiares, $u$ otros objetos de uso personal, no puede invocarse el interés social para recortar las atribuciones de uso y goce de la persona propietaria; mucho menos, privarla de la propiedad sobre tales bienes. Nuestro planteo interpretativo, en síntesis, parte de las normas más generales (el inviolable derecho de uso, goce y disposición, previsto en los arts. 14 y 17 de la CA) para luego incorporar los elementos más específicos: un criterio especial de regulación, en el art. 21 de la $\mathrm{CADH}$; una protección a ciertos bienes particulares, en el art. 23 de la DADDH.

De esta forma, podría concluirse que la función social de la propiedad sancionada en 1949 y proyectada en 1957 ha adquirido una nueva versión en 1994, con un nombre y un alcance diferentes. Consiste en la "subordinación al interés social" y en la tutela especial a ciertos bienes personales. No hay referencias específicas al latifundio ni se establece propiedad estatal sobre recursos naturales o monopolios sobre servicios públicos, como en 1949 o 1957. Tampoco la expropiación aparece como un mecanismo especial para la "autodefensa" de la comunidad. La propiedad como título parece permanecer, pero el uso y goce en ciertos casos sufre limitaciones en aras del bien colectivo.

Esta propuesta ha sido objetada, en el marco de un valioso y amplio trabajo teórico, por José Sebastián Elías. Este autor considera que no resulta admisible interpretar los artículos 14 y 17 en conjunto con los preceptos de fuente internacional ${ }^{94}$. Dos son los puntos principales del cuestionamiento. El primero se centra en el alcance de las facultades de la Convención reformadora. Elias destaca que la ley 24.309 prohibía modificar los primeros 35 artículos de la CA, lo que incluye a los citados preceptos sobre propiedad. Por lo tanto, la reforma no puede haber cambiado el alcance de este derecho. A esto podemos responder que el texto de los artículos 14 y 17 se mantiene intacto. Pero su interpretación no puede prescindir de otras pautas de igual jerarquía, tales como las contenidas en los tratados internacionales incluidos en el inc. 22 del art. 75. Del mismo modo, la libertad de expresión consagrada en el art. 14 debe leerse en conjunto con el art. 13 de la CADH, por ejemplo. Esto no altera el texto del art. 14, pero sí modifica el alcance del derecho en cuestión (que puede estar definido por uno o

94 Elias, José Sebastián, "El derecho de propiedad en la Constitución Nacional: una introducción teórica”, en Rivera, Julio César (h), Elias, José Sebastián, Grosman, Lucas Sebastián y Legarre, Santiago (directores), Tratado de los derechos constitucionales, Abeledo-Perrot, Buenos Aires, 2014, tomo II, pp. 703-705. 
más artículos, contenidos en el texto de la CA o en instrumentos con su mismo rango). Si se prescinde de los instrumentos dotados de jerarquía constitucional para interpretar los derechos consagrados en los primeros 35 artículos de la CA, la Convención de 1994 habría dividido la Constitución en dos partes, dándole preeminencia a la primera. Ello no se hizo, y tampoco lo autorizaba la ley 24.309. Como señalamos antes, la interpretación sistemática obliga a tener en consideración todas las pautas de igual jerarquía. Del mismo modo, la adopción de mecanismos de democracia semidirecta (arts. 39 y 40) incide en los arts. 1 y 22, que establecen la forma representativa de gobierno, pero no modifica su texto. Solamente exige encontrar una lectura armónica entre las cuatro disposiciones. Lo mismo ocurre con los artículos 14 y 17 del texto constitucional y los artículos 21 de la CADH y 23 de la DAADH.

El segundo argumento de Elías se basa en la distinción entre derecho internacional y derecho interno. El criterio del "interés social" se halla en la CADH y no en el articulado constitucional. El art. 29 de la CADH prohíbe utilizar las cláusulas de ese tratado para limitar el goce y ejercicio de un derecho reconocido en el derecho interno del Estado parte (inc. b). Se busca así proteger la formulación de derechos más amplia, en beneficio de las personas. Aplicándolo en el caso de la propiedad, Elías considera que el "interés social” incluido en la $\mathrm{CADH}$ representa una limitación mayor a la admitida en los artículos 14 y 17 de la Constitución argentina. Por lo tanto, no puede utilizarse: debe prevalecer la versión más extensa del derecho de propiedad adoptada en 1853.

En nuestra opinión, este razonamiento es correcto solo desde la perspectiva del operador de derecho internacional. Un órgano de aplicación de la CADH (por ejemplo, la Corte Interamericana) podría comparar el derecho de propiedad formulado en 1853 con el vigente en el tratado interamericano y concluir -como lo hace Elías- que el primero es más amplio ya que no está sometido al "interés social" como criterio específico de limitación.

Pero volvamos ahora al punto de vista constitucional (o de derecho doméstico). En este plano, todos los artículos (los de 1853 y los contenidos en la $\mathrm{CADH}$ ) tienen la misma jerarquía. Por lo tanto, no hay dos versiones del derecho de propiedad que puedan compararse (como ocurre bajo la perspectiva internacional). En el derecho interno hay una sola versión: la definida a partir de todas las disposiciones de rango constitucional, interpretadas de manera armónica. La separación entre derecho internacional y derecho interno no resulta aplicable cuando se trata de definir el alcance constitucional de derechos consagrados en artículos de la CA y tratados de derechos humanos dotados de igual jerarquía. Alli deben armonizarse todas esas cláusulas, como ocurre cuando dos artículos de la CA tratan el mismo tema.

Retomando la objeción de Elías, entendemos que no puede prescindirse de la $\mathrm{CADH}$ para dar prevalencia a otros artículos. La CADH -y el resto de instrumentos internacionales de igual rango- forman parte del material a interpretar junto a todos los artículos de la CA, del 1 al 129. Por lo tanto, la reforma de 1994 sí modificó el alcance del derecho de propiedad: a las pautas del siglo XIX agregó -sin alterar el texto de los artículos- otras cláusulas de la misma jerarquía (en este caso, las de los tratados). El trabajo de hallar una lectura armónica es exigente; y nuestra propuesta con toda seguridad puede ser mejorada. No es posible, sin embargo, eludir la tarea hermenéutica mediante la exclusión de las normas integradas a través del inc. 22 del art. 75. El permanente 
diálogo social sobre la interpretación constitucional, sostenido entre la ciudadanía y las instituciones, permitirá consolidar la mejor lectura que logre la vigencia simultánea y plena de todo el bloque constitucional argentino.

\section{PALABRAS FINALES.}

Hemos conducido un recorrido por tres momentos de la historia constitucional argentina del siglo $\mathrm{XX}$ a fin de comprender cómo la función social de la propiedad llegó a las páginas de la CA y luego fue eliminada. En general, se partió de reconocer la necesidad de regular de modo especial el derecho de propiedad, superando la noción clásica del texto de 1853, que contaba con tutelas especiales. El influjo del pensamiento social cristiano y de la teoría de Léon Duguit, entre otras corrientes, abrió paso a la consagración constitucional de la función social de la propiedad en la CA1949, que insertaba esta pauta en un modelo económico más amplio, centrado en la intervención estatal. Señalamos que, a pesar de las intenciones iniciales, la eliminación de los latifundios no pudo fijarse como un objetivo constitucional en Argentina. La derogación por proclama del texto sancionado en 1949 restauró la visión liberal de la propiedad adoptada en 1853. Durante la reforma de 1957, el intento de restablecer el Estado social en la CA no llegó a cumplirse del todo. Jaqueada por sus problemas de legitimidad de origen y la retirada de varios integrantes, la Convención de 1957 solo alcanzó a incorporar un artículo con derechos sociales, pero fue imposible aprobar la cláusula proyectada sobre función social de la propiedad, que resultaba -en algunos aspectos- más avanzada que la de 1949.

La reforma de 1994 incorporó nuevas pautas para la definición del derecho de propiedad. Si bien no alteró las cláusulas aprobadas en el siglo XIX, base de la concepción liberal de este derecho, dio jerarquía constitucional a tratados de derechos humanos que - redactados en el marco del pensamiento de posguerraparecen aproximarse a la noción de función social de la propiedad. En ese marco, discutimos una forma de interpretar armónicamente las viejas y nuevas cláusulas, hoy integradas en un bloque normativo de jerarquía homogénea. En nuestra opinión, la reforma de 1994 modificó -quizá inadvertidamente- el contenido del derecho constitucional de propiedad en Argentina, habilitando su regulación más intensa en ciertos casos y protegiendo especialmente a los bienes más cercanos a la persona, su dignidad y su hogar. Ello se aproxima a la noción de función social de la propiedad, si bien esa denominación no ha sido consagrada. Consideramos que el debate interpretativo continuará en el futuro cercano. Nuestra intención ha sido contribuir a la discusión y tratar de integrarla en una continuidad histórica.

\section{BIBLIOGRAFÍA}

Abásolo, Ezequiel, "La Corte Suprema durante el régimen peronista (1947-1955)", en Santiago, Alfonso (h) (dir.), Historia de la Corte Suprema argentina, Marcial Pons, Buenos Aires, 2013, tomo II, pp. 481-526.

Aboy Carlés, Gerardo, "Raúl Alfonsín y la fundación de la 'segunda república'”, en Gargarella, Roberto, Murillo, Maria Victoria y Pecheny, Mario (comp.), Discutir Alfonsin, Siglo XXI, Buenos Aires, 2010, pp. 67-84. 
Abramovich, Victor y Courtis, Christian, Los derechos sociales como derechos exigibles, Trotta, Madrid, 2002.

Alice, Beatriz L., "Acrecimiento de derechos y garantías y creación de órganos de control en la reforma constitucional de 1994", en Ekemekdjian, Miguel Ángel y Ferreyra, Raúl Gustavo (coord.), La reforma constitucional de 1994 y su influencia en el sistema republicano y democrático, Depalma, Buenos Aires, 2000, pp. 35-56.

Ankersen, Thomas y Ruppert, Thomas, "Tierra y libertad: the social function doctrine and land reform in Latin America", Tulane Environmental Law Journal, vol. 19, 2006, pp. 69-120.

Antoni, Norberto, "Los derechos sociales en la Constitución Nacional argentina de 1949", en Valle, Adolfo, Subordinación y contrato de trabajo, s. e., Buenos Aires, 1950.

Badeni, Gregorio, Instituciones de derecho constitucional, Ad Hoc, Buenos Aires, 1997.

Bidart Campos, Germán J., Tratado elemental del derecho constitucional argentino (vol. I-A), Ediar, Buenos Aires, 2000.

Cantón, Darío y Moreno, José Luis, "La experiencia radical (1916-1930)", en Cantón, Darío, Moreno, José Luis y Ciria, Alberto, Argentina. La democracia constitucional y su crisis, Paidós, Buenos Aires, 1980, pp. 13-120.

Cayuso, Susana, Constitución de la Nación Argentina: claves para el estudio inicial de la norma fundamental, La Ley, Buenos Aires, 2006.

Consejo para la Consolidación de la Democracia, Reforma Constitucional. Dictamen preliminar del Consejo para la Consolidación de la Democracia, Eudeba, Buenos Aires, 1986.

Dalla Vỉa, Alfredo, Derecho constitucional económico, LexisNexis, Buenos Aires, 2006.

De Imaz, José Luis, Los que mandan, Eudeba, Buenos Aires, 1964.

Diario de Sesiones de la Convención Nacional Constituyente. Año 1949, tomo I, Imprenta del Congreso de la Nación, Buenos Aires, 1949.

Diario de Sesiones de la Convención Nacional Constituyente. Año 1957, tomos I y II, Imprenta del Congreso de la Nación, Buenos Aires, 1958.

Ekmekdjian, Miguel A., Tratado de derecho constitucional, Depalma, Buenos Aires, 1994.

Elías, José Sebastián, "El derecho de propiedad en la Constitución Nacional: una introducción teórica”, en Rivera, Julio César (h), Elias, José Sebastián, Grosman, 
Lucas Sebastián y Legarre, Santiago (directores), Tratado de los derechos constitucionales, Abeledo-Perrot, Buenos Aires, 2014, tomo II, pp. 685-711.

Foster, Sheila R. y Bonilla, Daniel, "Symposium. The social function of property: a comparative law perspective. Introduction", Fordham Law Review, vol. 80, 2011, pp. 101-113.

Gelli, María Angélica, Constitución de la Nación Argentina.Comentada y concordada, 3a edición, La Ley, Buenos Aires, 2005

Lema Añón, Carlos, "Derechos sociales, ¿para quién? Sobre la universalidad de los derechos sociales", Derechos y libertades, núm. 22, 2010, pp. 179-203.

Lhöest, Brigitte F. P., "Constitutional reform in Argentina", Verfassung und Recht in Übersee / Law and Politics in Africa, Asia and Latin America, vol. 28, núm. 2, 1995, pp. 155-165.

Mansilla, César L., Las fuerzas de Centro, Centro Editor de América Latina, Buenos Aires, 1983.

Midón, Mario A. R., Manual de derecho constitucional argentino, Plus Ultra, Buenos Aires, 1997.

Odena, Isidoro J., Libertadores y desarrollistas 1955-1962, La Bastilla, Buenos Aires, 1988.

Oszlak, Oscar, La formación del estado argentino, Editorial de Belgrano, Buenos Aires, 1982.

Palacio, Juan Manuel, La justicia peronista. La construcción de un nuevo orden legal en la Argentina, Siglo XXI, Buenos Aires, 2018.

Palermo, Vicente y Novaro, Marcos. Politica y poder en el gobierno de Menem. Norma, Buenos Aires, 1996.

Pasquale, Florencia, "La función social de la propiedad en la obra de Léon Duguit: una re-lectura desde la perspectiva historiográfica", Historia Constitucional, núm. 15, 2014, pp. 93-111.

Quiroga Lavié, Humberto, Constitución de la Nación Argentina. Comentada, Zavalia, Buenos Aires, 2000.

Ramella, Susana, "Propiedad en función social en la Constitución de 1949. Una 'mentalidad' del Antiguo Régimen representada en el constitucionalismo social de la época", Revista de Historia del Derecho, núm. 35, 2007, pp. 297-354.

Rapoport, Mario et al., Historia económica, politica y social de la Argentina (18802000), Macchi, Buenos Aires, 2000.

Rodríguez Lamas, Daniel, La Revolución Libertadora, Centro Editor de América 
Latina, Buenos Aires, 1985.

Romero, César Enrique, Esbozo histórico del Estado y sus direcciones contemporáneas, Dirección General de Publicaciones de la Universidad Nacional de Córdoba, Córdoba, 1955.

Rouquié, Alain, Poder militar y sociedad politica en la Argentina. 1943-1973, Emecé, Buenos Aires, 1982.

Sagüés, Néstor P., Elementos de Derecho Constitucional, Astrea, Buenos Aires, 1999.

Serafin, Albino, 1955. Revolución Libertadora. Gobierno y partido de la UCRI en Córdoba, Narvaja Editor, Córdoba, 1994.

Sunstein, Cass R., The second bill of rights. FDR's unfinished revolution and why we need it more than ever, Basic Books, Nueva York, 2004

Tanzi, Héctor José, "La Corte Suprema del individualismo liberal (1903-1930)", en Santiago, Alfonso (h) (director), Historia de la Corte Suprema argentina, Marcial Pons, Buenos Aires, 2013, tomo I, pp. 197-287.

Unamuno, Miguel y Bortnik, Rubén, La reforma constitucional en el siglo XX, Centro Editor de América Latina, Buenos Aires, 1986.

Vanossi, Jorge R., El Estado de Derecho en el constitucionalismo social, Eudeba, Buenos Aires, 1987.

Enviado el (Submission Date): 26/10/2018.

Aceptado el (Acceptance Date): 12/12/2018 